\title{
Different approaches for aesthetic rehabilitation of discolored nonvital anterior teeth
}

\author{
Diferentes abordagens para reabilitação estética de \\ dentes anteriores escurecidos não-vitais
}

\author{
Pâmella Coelho DIAS1 iD https://orcid.org/0000-0003-4886-3940 \\ Fernanda Blanco Machado Junqueira FRANCO ${ }^{1}$ iD https://orcid.org/0000-0003-1091-866X \\ Regina Guenka PALMA-DIBB ${ }^{1}$ iD https://orcid.org/0000-0002-3247-0248 \\ Rafael Cândido Pedroso e SILVA ${ }^{1}$ iD https://orcid.org/0000-0002-5931-6750 \\ Juliana Jendiroba FARAONI ${ }^{\text {iD }}$ https://orcid.org/0000-0003-0945-4028
}

\section{ABSTRACT}

An ideal aesthetic standard consists of facial and smile harmony. Discolored teeth generally cause an imbalance in facial aesthetics, leading to low self-esteem and disturbance in social relationships. Causes of teeth discoloration are classified as intrinsic or extrinsic. Bleaching is considered a safe and effective treatment for discolored nonvital teeth and can be associated with restorative treatment to properly correct the dental color and maximize the aesthetic results. This paper aims to present two case reports of single discolored nonvital anterior teeth and the protocol used to reestablish the dental harmony of these patients by bleaching and direct composite resin restoration. To exert minimally invasive dentistry is very important to preserve tooth structure and reduce the risk of fracture. Internal bleaching, although may not be sufficient to reestablish the aesthetic in some cases, it is important to minimize dental preparation to perform an indirect or direct restoration. Dentists must take into account the patients expectations, dominate the restorative technique and know the dental materials to properly be able to restore function and aesthetics and consequently improve life quality and social relationships.

Indexing terms: Aesthetics. Tooth bleaching. Tooth discoloration.

\section{RESUMO}

Um padrão estético ideal consiste na harmonia facial e do sorriso. Dentes descoloridos geralmente causam um desequilibrio na estética facial, levando a baixa auto-estima e interferência nas relações sociais. As causas da descoloração dos dentes são classificadas como intrínsecas ou extrínsecas. O clareamento é considerado um tratamento seguro e eficaz para os dentes não vitais escurecidos e pode ser associado ao tratamento restaurador para corrigir adequadamente a cor dental e maximizar os resultados estéticos. O objetivo deste trabalho é apresentar dois relatos de casos de dentes anteriores não vitais escurecidos e o protocolo utilizado para restabelecer a harmonia dentária desses pacientes por meio de clareamento e restauração direta em resina composta. Para exercer uma Odontologia minimamente invasiva é muito importante preservar a estrutura dentária e reduzir o risco de fratura. O clareamento interno, embora possa não ser suficiente para restabelecer a estética em alguns casos, é importante para minimizar o preparo dental para realizar uma

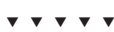

1 Universidade de São Paulo, Faculdade de Odontologia de Ribeirão Preto Departamento de Odontologia Restauradora. Av. do Café, s/n. 14040-904, Ribeirão Preto, SP, Brasil. Correspondence to: PC Dias. E-mail: <pamellacdias@hotmail.com>.

$\checkmark \nabla \nabla$

How to cite this article

Dias PC, Franco FBMJ, Silva RCP, Farani JJ. Aesthetic rehabilitation of discolored nonvital anterior teeth. RGO, Rev Gaúch Odontol. 2020;68: e20200035. http://dx.doi.org/10.1590/1981-863720200003920190174
} 
restauração indireta ou direta. Os dentistas devem levar em consideração as expectativas dos pacientes, dominar a técnica restauradora e conhecer os materiais dentários para poder restaurar adequadamente a função e a estética e, consequentemente, melhorar a qualidade de vida e as relações sociais.

Termos de indexação: Estética. Clareamento dental. Descoloração de dente.

\section{INTRODUCTION}

Aesthetics exerts a strong influence on our society, so an imbalance on the facial or smile harmony can have a negative impact in life quality, reducing self-esteem and disturbing social relationships.

Discolored teeth may be considered a negative factor in the concept of an ideal aesthetic standard and can be a challenging problem to be solved [1]. Causes of teeth discoloration are classified as intrinsic or extrinsic. Nonvital teeth may have color alteration especially due to dental trauma, pulpal necrosis, intrapulpal bleeding and endodontic materials, which are intrinsic discolorations [2].

However, nowadays exist several techniques and materials that allow the dentist to exert a minimally invasive dentistry, with conservation of the tooth structure and great aesthetical outcome [3], such as bleaching treatment and composite resin restorations [4].

Bleaching is considered a safe and effective treatment for discolored nonvital teeth $[2,3]$. The main bleaching agents are hydrogen peroxide, carbamide peroxide and sodium perborate and they act by the oxidation of organic compounds (chromophores). After oxidation, the chromophores are broken down into smaller molecules, which do not absorb light, leaving the teeth lighter [5].

Nonvital teeth bleaching can be performed by the walking bleach technique, the inside-outside technique or the in-office technique $[1,3]$. Some precautions should be taken to prevent the risk of cervical resorption which consists of the cervical sealing with glass ionomer or composite resins $[2,6]$. In the walking bleach technique the bleaching agent is inserted inside the pulp chamber and removed after 3-4 days [6]. The protocol can be repeated if necessary and this technique can be performed with sodium perborate, carbamide peroxide or hydrogen peroxide $[6,7]$. The inside-outside technique consists in protect the tooth with a cervical barrier and leave the access cavity open for the patient to directly apply the bleaching agent ( $10 \%$ carbamide peroxide) into the cavity and also on a bleaching tray. The tray is seated into the mouth to cover the cavity and the bleaching agent is changed every 4-6 hours. The patient returns to the dental office after 2-3 day to evaluate the whitening progress [8]. The inoffice technique (power bleaching) consists of applying the bleaching agent both inside the pulp chamber and on the dental surface. After the procedure, the agent is removed and the canal access is sealed with a temporarily material. Bleaching agents available for this procedure are carbamide and hydrogen peroxide in high concentrations [3].

Bleaching is a predictable treatment for endodontically treated teeth, especially for grey and dark yellow discolorations [9], although in some cases, depending on the dental saturation degree, pigmentation etiology and the results obtained after bleaching, it may also be necessary to associate a restorative treatment to properly correct the dental color and maximize the aesthetic results.

Adhesive restoration must be performed 1-3 weeks after bleaching, since the residual oxygen affects the restorative material bonding to the enamel and dentin, impairing the longevity of the restoration and color stability $[1,10]$.

The use of composite resins to masquerade discolored substrates should take in account the optical properties of the natural tooth, such as opalescence, translucency and also dental shape and surface textures [11]. The success of the restoration depends on the material choice and the applied technique [12].

This paper aims is to present two case reports of single discolored nonvital anterior teeth and the protocol used to reestablish the dental harmony of these patients by bleaching and direct composite resin restoration.

\section{CASE REPORTS}

\section{Case 1}

A 28-year-old woman attended the Restorative Dentistry Clinic of São Paulo University, Ribeirão Preto, Brazil, complaining about the color of her anterior tooth. 
After anamnesis, the clinical evaluation showed a dark gray coloration at her lower left central incisor (tooth 31), besides a small incisal fracture at the same tooth (figure $1 \mathrm{~A}$ and $1 \mathrm{~B}$ ). The patient reported that she fell and suffered a dental trauma when she was 9 years-old. She went under orthodontic treatment and only noticed the tooth discoloration after braces removal in 2004. The tooth went through endodontic treatment in this same year and an attempt of bleaching was performed in 2008 without results. Radiographic examination showed satisfactory endodontic treatment and no periapical alterations (figure 1C).

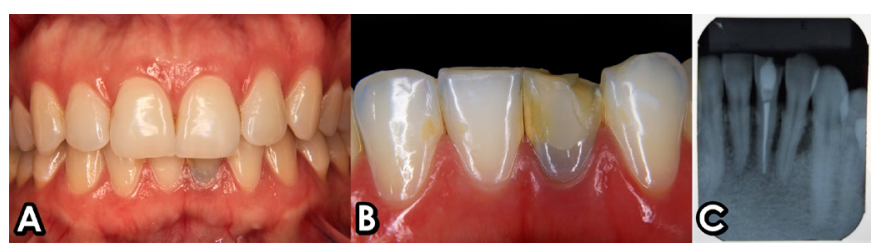

Figure 1. Initial clinical evaluation. (A) Smile aspect evidencing tooth 31 discoloration. (B) Tooth 31 presenting gray discoloration and labial and distal incisal fracture. (C) Radiography of tooth 31 showing satisfactory endodontic treatment and no periapical alterations.

The initial color was registered with photos and VITA scale (VITA-Zahnfabrik H. Rauter Gmbh \& Co. KG, Bad Säckingen, Germany). The operative field was isolated with a rubber dam and the restorative material removed. The dental crown length was measured with a periodontal probe and $4.0 \mathrm{~mm}$ of gutta percha was removed to allow the insertion of a $2.0 \mathrm{~mm}$ cervical barrier with glass ionomer (Ketac TM Molar Easy Mix, 3M ESPE, Maplewood, Minnesota, USA) until the amelocemental junction limit. It was performed three sessions of bleaching by the in-office technique under absolute isolation. In each session a $35 \%$ hydrogen peroxide gel (Potenza Bianco Pro, PHS do Brasil, Joinville, Santa Catarina, Brazil) was inserted inside the pulp chamber and on the labial and lingual surface of tooth 31 . The gel was changed three times every 15 minutes, then the cavity was rinsed with abundant water, dried by air blast, and covered with a small cotton ball and a temporarily restorative material (Villevie, Dentalville do Brasil, Joinville, Santa Catarina, Brazil).

The color-changing was registered in every clinical session, and after the internal bleaching an alginate impression (Hydrogun, Zhermack, Badia Polesine, Italy) was taken to fabricate a whitening tray for at-home bleaching. The patient used the tray 3-hours a day for 21 days in upper and lower teeth (Whiteness Perfect - 16\% carbamide peroxide, FGM, Joinville, Santa Catarina, Brazil). The result was satisfactory and 30 days after bleaching the tooth was restored, however after 2 months it was noted a slight regression of the color in tooth 31 (figure 2A).

Since this tooth went through dental bleaching before, two months after the tooth restoration a direct composite resin veneer to mask the gray substrate was performed. Minimally invasive tooth preparation was made with diamond burs 1014 - cervical region and 2143 proximal region and labial surface (KG Sorensen, Medical Burs Ind. e Com. de Pontas e Brocas Cirúrgicas Ltda., Cotia, São Paulo, Brazil) (figure $2 \mathrm{~B}$ and $2 \mathrm{C}$ ). The anterior teeth were isolated with a rubber dam and the enamel was conditioned with $37 \%$ fosforic acid (Condac 37, FGM, Joinville, Santa Catarina, Brazil) and a single step self-etch bonding agent (BeautiBond, Shofu Inc., Kyoto, Japan) was used in both enamel and dentin. The gray substrate was masked with an opaque resin - BW (Beautifil, Shofu Inc., Kyoto, Japan). The composite resin (Beautifil, Shofu Inc., Kyoto, Japan) was applied on dentin and enamel with spatulas and textured with brushes. It was used two shades of resin: $A 2$ on the cervical third and $A 1$ on the middle and incisal third of the tooth. The last resin layer was made with a translucent resin - T (Beautifil, Shofu Inc., Kyoto, Japan).

Occlusal contacts were checked and adjusted with a double-sided occlusal marking film (AccuFilm $®$ II, Parkell, Edgewood, New York, USA). Cervical excesses of the composite material were removed with FF Diamond tips (KG Sorensen, Medical Burs Ind. e Com. de Pontas e Brocas Cirúrgicas Ltda., Cotia, São Paulo, Brazil) and multi-laminated burs (Prima Dental, Angelus, Londrina, Paraná, Brazil) (figure 2D) and a finishing strip (Microdont, São Paulo, São Paulo, Brazil) was used in the interproximal surface. For polishing, decrescent granulation of abrasive tips (American Burrs, Palhoça, Santa Catarina, Brazil) associated with a composite polishing paste (Diamond Excel, FGM, Joinville, Santa Catarina, Brazil) was used on the restoration. High gloss polishing was obtained by CeraMaster tip (Shofu Inc., Kyoto, Japan) and felt disc (Diamond Flex, FGM, Joinville, Santa Catarina, Brazil) (Figure 2E and 2F). Figure 3A and 3B show the result of the restoration.

The patient had a high level of aesthetic expectation as she had a history of failed attempts to 
restore the discolored tooth. Although she experienced a slight regression of the tooth color during treatment, after

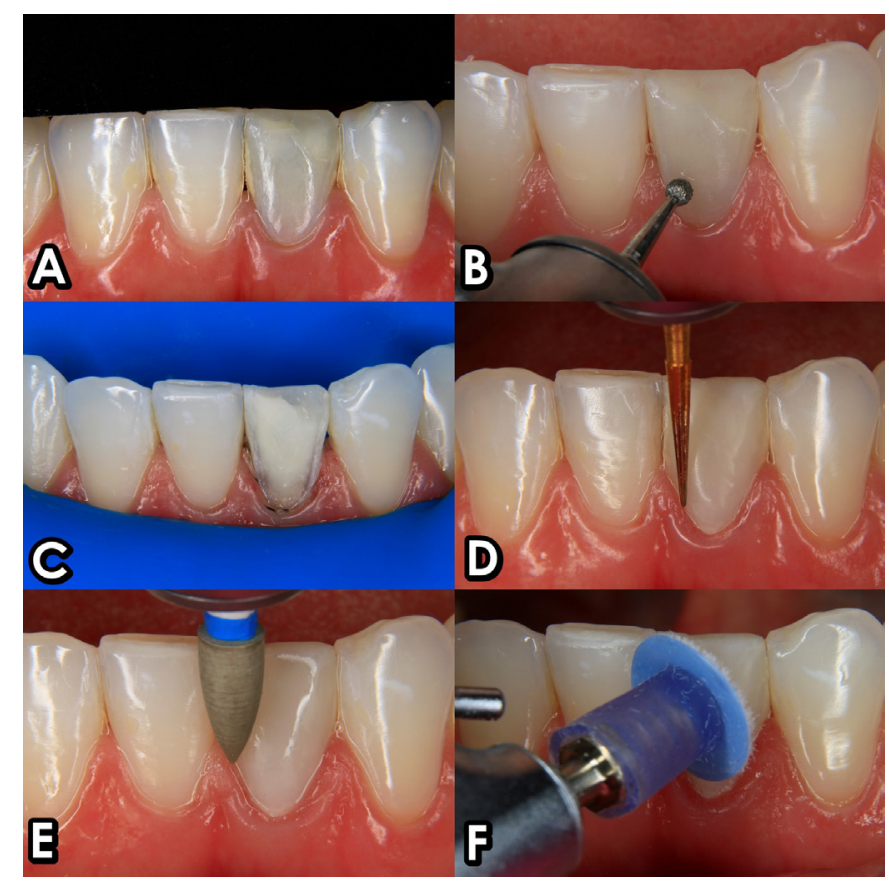

Figure 2. (A) Tooth 31 showing color regression two months after restoration. (B) Tooth preparation with a 1014 diamond tip. (C) Tooth prepared. (D) Dental finishing with multi-laminated bur. (E) Dental polishing with CeraMaster tip. (F) Felt disc.

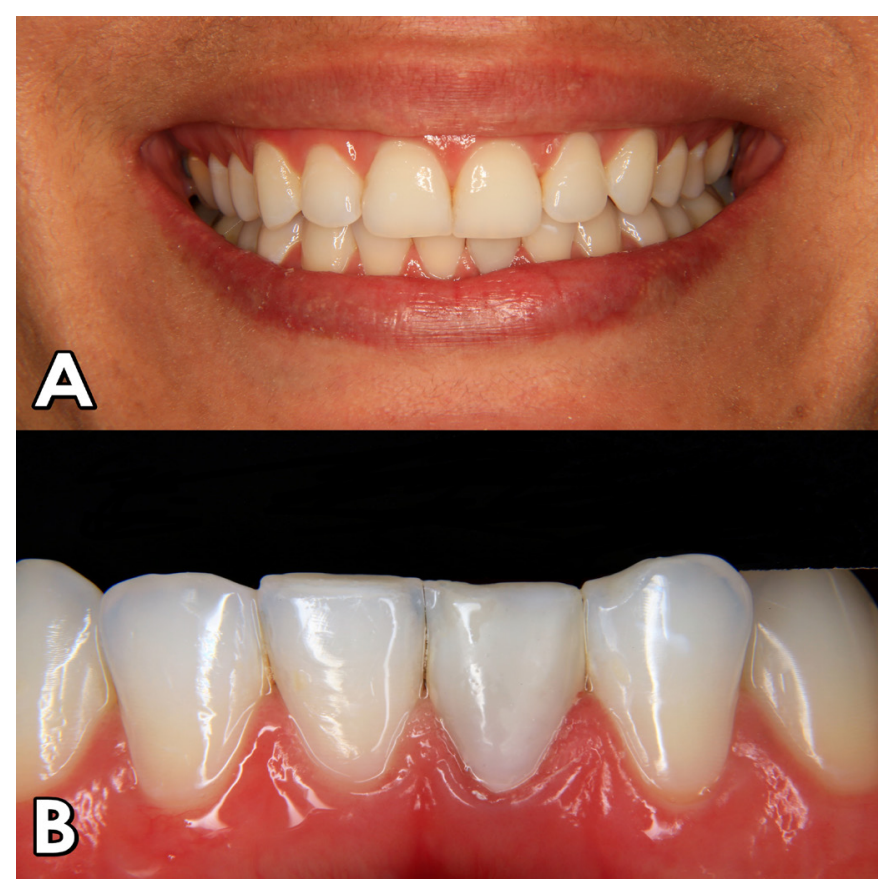

Figure 3. Final aspect of the direct restoration of tooth 31. (A) Smile. (B) Close-up of the restoration. the restoration with a direct veneer, the result was very satisfactory and reached her expectations.

\section{Case 2}

A 24-year-old woman attended the Restorative Dentistry Clinic of São Paulo University, Ribeirão Preto, Brazil, complaining about the appearance of her smile. After anamnesis, the clinical evaluation showed a yellow coloration at her upper right central incisor (tooth 11) and an extensive distal class IV restoration (figure 4A and 4B). The patient reported that she fell and suffered a dental trauma when she was 9 years old and restored the tooth with composite resin. When she was 15 years old after a radiographic exam the orthodontist noted the necessity to perform an endodontic treatment in tooth 11 . The tooth was endodontically treated in 2009 and discolored two years ago. Radiographic examination showed satisfactory endodontic treatment and no periapical alterations (figure 4C).

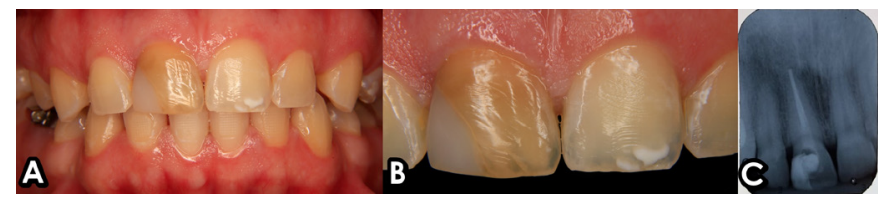

Figure 4. Initial clinical evaluation. (A) Smile aspect evidencing tooth 11 discoloration. (B) Tooth 11 presenting yellow discoloration and an extensive distal class IV restoration of composite resin. (C) Radiography of tooth 11 showing satisfactory endodontic treatment and no periapical alterations.

The initial color was registered with photos and the VITA scale (VITA-Zahnfabrik H. Rauter Gmbh \& Co. $K G$, Bad Säckingen, Germany). The operative field was isolated with a rubber dam and the restorative material was removed. The dental crown length was measured with a periodontal probe and $4.0 \mathrm{~mm}$ of gutta percha was removed to allow the insertion of a $2.0 \mathrm{~mm}$ cervical barrier with glass ionomer (Ketac ${ }^{\mathrm{TM}}$ Molar Easy Mix, 3M ESPE, Maplewood, Minnesota, USA). It was performed four sessions of bleaching by the in-office technique under absolute isolation. In each session, a 35\% hydrogen peroxide gel (Whiteness HP, FGM, Joinville, Santa Catarina, Brazil) was inserted inside the pulp chamber and on the labial and palatal surface of tooth 11. The gel was changed 
three times every 15 minutes, then the cavity was rinsed with abundant water, dried by air blast and covered with a small cotton ball and a temporarily restorative material (Villevie, Dentalville do Brasil, Joinville, Santa Catarina, Brazil). The color changing was registered in every clinical session and after the internal bleaching an alginate impression (Hydrogun, Zhermack, Badia Polesine, Italy) was taken to fabricate a whitening tray for at-home bleaching. The patient used the tray 3-hours a day for 21 days in upper and lower teeth with $16 \%$ carbamide peroxide gel (Whiteness Perfect, FGM, Joinville, Santa Catarina, Brazil). The case presented a good result, but a direct veneer was still necessary to harmonize the color (Figure 5A). Since the tooth became fragile by structure loss and endodontic treatment, a fiberglass post was cemented to retain the composite resin restoration.

Under absolute isolation, the root canal of tooth 11 was prepared with Largo drills 1,2 and 3 . A total of $17 \mathrm{~mm}$ of gutta-percha was removed and radiography was taken to check post space preparation and select the diameter of the fiberglass post. A drill compatible with the chosen post - 2.0 DC-E (FGM, Joinville, Santa Catarina, Brazil) was used to improve its adaptation, and the fiberglass post $n^{\circ}$ 2 (White Post DC-E, FGM Joinville, Santa Catarina, Brazil) was clinically tested. The root canal was irrigated with sodium hypochlorite and sterile saline solution and dried with sterile paper cones. The fiberglass post was treated with $35 \%$ hydrogen peroxide for 60 s followed by water rinsing for 60s and air drying. Silane (Dentsply Sirona, York, Pennsylvania, USA) was applied with a microbrush and after its volatilization it was applied the bonding agent (Single Bond Universal, 3M ESPE Maplewood, Minnesota, USA). The fiberglass post was cemented with a dual curing self-adhesive resin cement (RelyX'TM U200, 3M ESPE Maplewood, Minnesota, USA) (figure 5B).

After post cutting the old restoration was removed and a minimally invasive tooth preparation was made with diamond burs 1014 - cervical region and 2143 - proximal region and labial surface (KG Sorensen, Medical Burs Ind. e Com. de Pontas e Brocas Cirúrgicas Ltda., Cotia, São Paulo, Brazil) (figure 5C).

Tooth 11 was total-etched with 37\% fosforic acid (Condac 37, FGM, Joinville, Santa Catarina, Brazil), followed by abundant water rinsing and then slighted dried with absorbent paper; the bonding agent (Ambar APS, FGM, Joinville, Santa Catarina, Brazil) was applied in two layers and light-cured for 20s. The direct composite resin restoration was built by the estratification technique. It was used an opaque resin - OM (Charisma ${ }^{\circledR}$ Diamond, Heraeus Kulzer, Hanau, Germany) to mask the discolored substrate, resin $\mathrm{A} 1 \mathrm{D}$ to mimic dentin and $\mathrm{A} 1 \mathrm{E}$ for the enamel layer (IPS Empress ${ }^{\circledR}$ Direct, Ivoclar Vivadent, Schaan, Liechtenstein).

Occlusal contacts were checked and adjusted with a double-sided occlusal marking film (AccuFilm $®$ II, Parkell, Edgewood, New York, USA). Cervical excesses of the composite material were removed with $\mathrm{F}$ and FF Diamond tips (KG Sorensen, Medical Burs Ind. e Com. de Pontas e Brocas Cirúrgicas Ltda., Cotia, São Paulo, Brazil) (figure 5D). Interproximal excesses of composite material were removed with a finishing strip (Microdont, São Paulo, São Paulo, Brazil) (Figure 5E). Polishing was performed with low abrasive aluminum oxide finishing disks (Sof-Lex PopOn, 3M ESPE, Maplewood, Minnesota, USA), followed by decrescent granulation of abrasive tips (American Burrs, Palhoça, Santa Catarina, Brazil) associated with a composite polishing paste (Diamond Excel, FGM Joinville, Santa Catarina, Brazil). High gloss polishing was obtained by Astropol HP (Ivoclar Vivadent Schaan, Liechtenstein) (figure 5F) and felt disc (Diamond Flex, FGM Joinville, Santa Catarina, Brazil). Figures $6 \mathrm{~A}$ and $6 \mathrm{~B}$ show the result of the restoration.

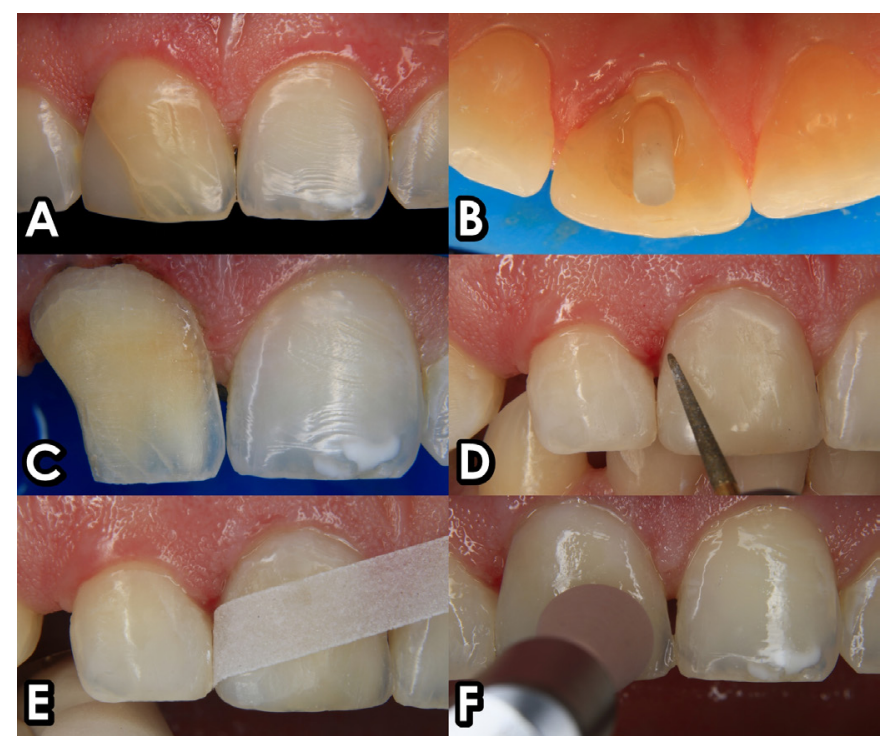

Figure 5. (A) Clinical aspect of tooth 11 after four internal bleaching sessions. (B) Post cementation. (C) Aspect of tooth 11 after restoration removal and direct veneer preparation. (D) Dental finishing with $F$ diamond tip. (E) Removal of interproximal excesses with a finishing strip. (F) High gloss polishing with Astropol. 


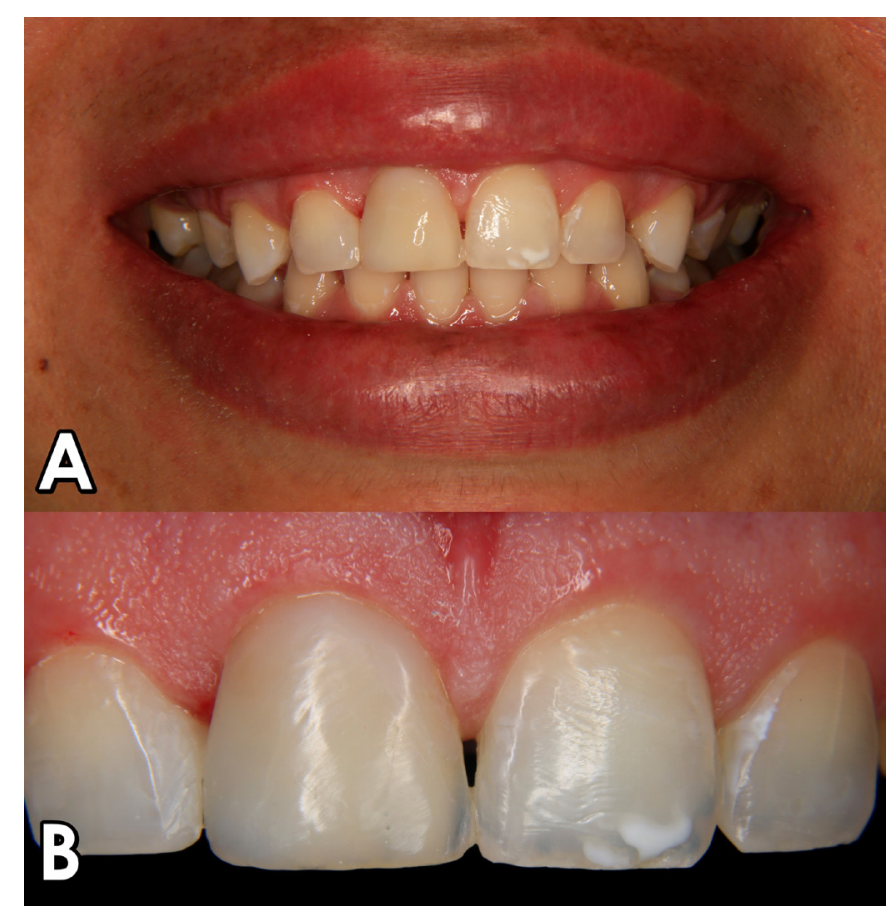

Figure 6. Final aspect of the direct restoration of tooth 11. (A) Smile. (B) Close-up of the restoration.

In this case, was noted throughout the bleaching sessions an increase in of the patient self-esteem as she started to talk and smile more. The opaque composite resin was able to masquerade the discolored substrate and the direct veneer presented a natural aspect fulfilling her expectations.

\section{DISCUSSION}

Internal bleaching is a viable alternative to perform a minimally invasive treatment since it allows a better preservation of dental structure and consequently the maintenance of the tooth mechanical properties reducing dental friability. Studies showed that this is a conservative, stable e safe procedure in addiction to have a positive impact in social aspects of life $[9,13]$.

Before bleaching, is important to remove $2.0 \mathrm{~mm}$ of gutta-percha below the cervical region to create space to seal the root canal with glass ionomer or composite resin to avoid root reabsorption $[2,6]$. In both case reports it was performed the in-office technique with hydrogen peroxide 35\% and periapical radiographs showed no sign of root reabsorption during and after treatment.

There are situations where dental bleaching is insufficient to restore the natural aspect of teeth, requiring direct or indirect procedures. These situations include color rebound and low alteration of the dental color [14]. In the cases described in this article, direct restorations with composite resins were required to properly rehabilitate the patient.

Direct restorations should not be performed immediately after bleaching since the tooth color is not stable yet which could compromise the composite selection and consequently the aesthetical result. Tooth color evaluation proved to show a significant difference between the day of the last bleaching session and the seven-day recall appointment for both in-office and athome bleaching techniques [15]. In both case reports presented in this article, the restorative procedures were performed at least four weeks after bleaching.

Case 1 showed a slight color rebound after two months of bleaching then the tooth was restored with a direct veneer. In a two-year evaluation study of nonvital teeth submitted to internal bleaching and composite resin restoration, it was observed color change between 2 weeks and 2 years of follow-up in 13 of 25 teeth. In this same study, the composite resin restoration showed no marginal discoloration and preservation of marginal integrity and anatomy. All teeth had class III or Class III and IV combined besides the canal access to be restored [16].

Some studies demonstrated higher fracture strength and greater longevity and success of treatment in teeth restored with fiberglass posts compared to teeth restored without fiber posts $[17,18]$ which might infer that fiber posts are indicated even for endodontically treated teeth with a conserved coronal portion. Despite these results others studies showed that the association of fiberglass posts and composite resins do not reinforce the dental element $[19,20]$. Case 1 presented a tooth with a great remaining substrate so a minimal preparation was performed for the direct veneer without the use of a fiberglass post. Differently, the treatment plan in case 2 included a fiberglass post since tooth 11 presented an extensive and unsatisfactory class IV restoration, besides the necessity to perform a direct veneer preparation, as internal bleaching was insufficient to equalize the dental substrate with the adjacent teeth.

Regarding the post cementation technique, the fiberglass post surface was treated with hydrogen peroxide since several studies demonstrated an increase in bond strength when the peroxide was applied before the silane 
coupling agent [21-23]. Hydrogen peroxide acts partially dissolving the epoxy resin present on fiber posts exposing the glass fibers, which enhances micromechanical retention [24].

Photoactivation timing delay of a dual luting agent showed to enhance bond strength and decrease residual shrinkage [25]. In case 2 photoactivation was performed 5 minutes after post cementation and excess removal [25]. To execute the case it was used the self-adhesive resin cement Rely X U200 (3M ESPE, Maplewood, Minnesota, USA) and the post was cut after luting. According to Borges et al. [26], this protocol does not affect retention to root dentin when this type of luting agent is used.

To restore both teeth of these case reports it was used opaque, enamel and dentin composite resins by the stratification technique. A two-year study that evaluated nonvital bleached teeth and its composite resins restorations showed that the restorations presented excellent clinical performance [26].

Abott \& Heah [9] analyzed the internal bleaching outcome of 255 teeth and observed that all teeth had positive results related to color change (acceptable or good) and there were no cases without any changes. These results highlight that internal bleaching is a viable option for discolored nonvital teeth even in cases that do not manage to achieve the ideal color, since greater tooth structure could be preserved after preparation for a direct veneer.

\section{CONCLUSIONS}

The challenge of these cases was to properly mimic a natural aspect in the nonvital discolored teeth as they are located in the anterior region of the smile exerting a strong influence on dental and facial harmony. Since both situations presented a single tooth to be restored, the difficulty to equalize the dental substrate with the adjacent teeth was bigger than in multiple teeth restoration cases.

To exert minimally invasive dentistry is very important to preserve tooth structure and reduce the risk of fracture. Internal bleaching, although may not be sufficient to reestablish the aesthetic in some cases, it is important to minimize dental preparation to perform an indirect or direct restoration. Dentists must take into account the patients' expectations, dominate the restorative technique and know the dental materials to properly be able to restore function and aesthetics and consequently improve life quality and social relationships.

\section{Collaborators}

PC DIAS, conceptualization, methodology, writingoriginal draft. FBMJ FRANCO, methodology, writing-original draft. RG PALMA-DIBB, project administration, writing-review \& editing. RC PEDROSO e SILVA, supervision, writing-review \& editing. JJ FARAONI, formal analysis, supervision and writingreview \& editing.

\section{Acknowledgements}

The authors would like to thank FUNORP (Fundação Odontológica de Ribeirão Preto) and School of Dentistry of Ribeirão Preto, University of São Paulo, SP, Brazil.

\section{REFERENCES}

1. Kwon SR. Whitening the single discolored tooth. Dent Clin North Am. 2011;55(2):229-39. http://dx.doi.org/10.1016/j. cden.2011.01.001

2. Zimmerli B, Jeger F, Lussi A. Bleaching of nonvital teeth. Schweiz Monatsschr Zahnmed. 2010;120(4):306-20.

3. Nixon PJ, Gahan M, Robinson S, Chan MF-Y. Conservative aesthetic techniques for discoloured teeth: 1. The use of bleaching. Dent Update. 2007;34(2):98-100. http://dx.doi. org/10.12968/denu.2007.34.2.98

4. Dietschi D. Optimizing smile composition and esthetics with resin composites and other conservative esthetic procedures. Eur J Esthet Dent. 2008;3(1):14-29.

5. Sulieman MAM. An overview of tooth-bleaching techniques: chemistry, safety and efficacy. Periodontol 2000. 2008;48:148-69. http://dx.doi.org/10.1111/j.1600-0757.2008.00258.x

6. Attin T, Paque F, Ajam F, Lennon A. Review of the current status of tooth whitening with the walking bleach technique. Int Endod J. 2003;36(5):313-29. http://dx.doi.org/10.1046/ j.1365-2591.2003.00667.x

7. Bersezio C, Martín J, Peña F, Rubio M, Estay J, Vernal $\mathrm{R}$, et al. Effectiveness and impact of the walking bleach technique on esthetic self-perception and psychosocial factors: a randomized double-blind clinical trial. Oper Dent. 2017;42(6):596-605. http://dx.doi.org/10.2341/16-133-C

8. Greenwall-Cohen J, Greenwall LH. The single discoloured tooth: vital and non-vital bleaching techniques. $\mathrm{Br}$ Dent J. 2019;226(11):839-849. http://dx.doi.org/10.1038/s41415-0190373-9

9. Abbott $P$, Heah S. Internal bleaching of teeth: an analysis of 255 teeth. Aust Dent J. 2009;54(4):326-33. http://dx.doi. org/10.1111/j.1834-7819.2009.01158.x 
10. Attin T, Hannig C, Wiegand A, Attin R. Effect of bleaching on restorative materials and restorations - a systematic review. Dent Mater. 2004;20(9):852-61. http://dx.doi.org/10.1016/j. dental.2004.04.002

11. Miotti L, Santos I, Nicoloso G, Pozzobon R, Susin A, Durand $\mathrm{L}$. The use of resin composite layering technique to mask discolored background: A CIELAB/CIEDE2000 analysis. Oper Dent. 2017;42(2):165-174. http://dx.doi.org/10.2341/15-368-L

12. Dietschi D, Fahl Jr N. Shading concepts and layering techniques to master direct anterior composite restorations: an update. Br Dent J. 2016;221(12):765-771. http://dx.doi.org/10.1038/ sj.bdj.2016.944

13. Bersezio C, Martín J, Mayer C, Rivera O, Estay J, Vernal R, et al. Quality of life and stability of tooth color change at three months after dental bleaching. Qual Life Res. 2018;27(12):3199-3207. http://dx.doi.org/10.1007/s11136-018-1972-7

14. Andreas S, Osela V, Maria A, Maria A. Masking the discolored enamel surface with opaquers before direct composite veneering. J Dent Oral Disord Ther. 2015;3:1-8.

15. Deliperi S, Bardwell DN, Papathanasiou A. Clinical evaluation of a combined in-office and take-home bleaching system. J Am Dent Assoc. 2004;135(5):628-634. http://dx.doi. org/10.14219/jada.archive.2004.0252

16. Deliperi S, Bardwell DN. Two-year clinical evaluation of nonvital tooth whitening and resin composite restorations. J Esthet Restor Dent. 2005;17(6):369-78. http://dx.doi. org/10.1111/j.1708-8240.2005.tb00472.x

17. Clavijo VGR, Reis JMSN, Kabbach W, Oliveira Junior OB, Andrade MF. Fracture strength of flared bovine roots restored with different intraradicular posts. J Appl Oral Sci. 2009;17(6):574-8. http://dx.doi.org/10.1590/s1678-77572009000600007

18. Guldener KA, Lanzrein CL, Guldener BES, Lang NP, Ramseier CA, Salvi GE. Long-term clinical outcomes of endodontically treated teeth restored with or without fiber post-retained single-unit restorations. J Endod. 2017;43(2):188-193. http:// dx.doi.org/10.1016/j.joen.2016.10.008

19. Azevedo RA, Silva-Sousa YTC, Souza-Gabriel AE, Messias DCF, Alfredo $E$, Silva RG. Fracture resistance of teeth subjected to internal bleaching and restored with different procedures.
Braz Dent J. 2011;22(2):117-21. http://dx.doi.org/10.1590/ s0103-64402011000200005

20. Roberto AR, Sousa-Neto MD, Viapiana R, Giovani AR, Souza Filho $C B$, Paulino $S M$, et al. Effect of different restorative procedures on the fracture resistance of teeth submitted to internal bleaching. Braz Oral Res. 2012;26(1):77-82. http:// dx.doi.org/10.1590/s1806-83242012000100013

21. Dalitz F, de Oliveira Junior OF, Hintz RC, Correr GM, da Cunha $L F$, Gonzaga CC. Effect of hydrogen peroxide and universal adhesive application on the bond strength of glass fiber posts. Braz J Oral Sci 2017;160:1. http://dx.doi.org/10.20396/ bjos.v16i0.8651187

22. Valdivia ADCM, Novais VR, Menezes MS, Roscoe MG, Estrela C, Soares CJ. Effect of surface treatment of fiberglass posts on bond strength to root dentin. Braz Dent J. 2014;25(4):314-20. http://dx.doi.org/10.1590/0103-6440201300143

23. Vano M, Goracci C, Monticelli F, Tognini F, Gabriele M, Tay F, et al. The adhesion between fibre posts and composite resin cores: the evaluation of microtensile bond strength following various surface chemical treatments to posts. Int Endod J. 2006;39(1):31-9. doi: 10.1111/j.1365-2591.2005.01044.x.

24. Menezes MS, Queiroz EC, Soares PV, Faria-e-Silva AL, Soares CJ, Martins LRM. Fiber post etching with hydrogen peroxide: effect of concentration and application time. J Endod. 2011;37(3):398-402. http://dx. doi.org/10.1016/j. joen.2010.11.037

25. Pereira R, Valdívia A, Bicalho A, Franco S, Tantbirojn D, Versluis $A$, et al. Effect of photoactivation timing on the mechanical properties of resin cements and bond strength of fiberglass post to root dentin. Oper Dent. 2015;40(5):E206-21. http:// dx.doi.org/10.2341/14-115-L

26. Borges MG, Faria-e-Silva AL, Santos-Filho PC, Silva FP, Martins LR, Menezes MS. Does the moment of fiber post cutting influence on the retention to root dentin? Braz Dent J. 2015;26(2):141-5. http://dx.doi.org/10.1590/01036440201300242

Received on: 24/1/2020

Final version resubmitted on: 25/2/2020

Approved on: 3/3/2020 